Research Article

\title{
Morphological variation in a secondary contact between divergent lineages of brown trout (Salmo trutta) from the Iberian Peninsula
}

\author{
Miguel Hermida, Eduardo San Miguel, Carmen Bouza, Jaime Castro and Paulino Martínez \\ Departamento de Genética, Facultad Veterinaria, Universidad de Santiago de Compostela, Lugo, Spain.
}

\begin{abstract}
The aim of this study was to analyze the morphological variation of brown trout (Salmo trutta) in the Duero basin, an Atlantic river basin in the Iberian Peninsula, where a spatial segregation of two divergent lineages was previously reported, based on isozyme, microsatellite and mtDNA data. In these studies, two divergent pure regions (Pisuerga and Lower-course) and several hybrid populations between them were identified. Morphological variation was evaluated in 11 populations representative of the genetic differentiation previously observed in the Duero basin, using multivariate analysis on 12 morphometric and 4 meristic traits. A large differentiation between populations was observed (interpopulation component of variance: $41.8 \%$ ), similar to that previously detected with allozymes and microsatellites. Morphometric differentiation was also reflected by the high classification success of pure and hybrid individuals to their respective populations, using multivariate discriminant functions $(94.1 \%$ and $79.0 \%$, respectively). All multivariate and clustering analyses performed demonstrated a strong differentiation between the pure regions. The hybrid populations, though showing large differentiation among them, evidenced an intermediate position between the pure samples. Head and body shape traits were the most discriminant among the morphometric characters, while pectoral rays and gillrakers were the most discriminant among the meristic traits. These results confirmed the high divergence of the brown trout from the Duero basin and suggest some traits on which selection could be acting to explain the spatial segregation observed.
\end{abstract}

Key words: brown trout, secondary contact, morphometric, meristic, multivariate analysis.

Received: February 18, 2008; Accepted: August 12, 2008.

\section{Introduction}

The brown trout (Salmo trutta) is one of the most well researched European fish. It is also one of the vertebrate species with highest genetic subdivision (Ferguson, 1989). A pronounced genetic differentiation has been reported both at the microgeographic scale (Ryman, 1983; Crozier and Ferguson, 1986; Bouza et al., 1999) and along the geographic distribution range in this species. Five main phylogeographic lineages have been soundly identified using nuclear and mitochondrial DNA markers: Atlantic (AT), Mediterranean (ME), Adriatic (AD), Marmoratus (MA) and Danubian (DA) (Bernatchez, 2001; Presa et al., 2002). A sixth lineage (Duero: DU) was recently identified, restricted to the Duero and Miño basins in the Atlantic slope of the Iberian Peninsula (Suárez et al., 2001; Bouza et al., 2008). These lineages exhibited a strong spatial partitioning and seemed to have evolved in allopatry with limited introgression among them, though some evidence of hybridization and introgression was revealed when studying the rDNA ITS1 (Internal Transcribed Spacer 1) (Presa et al., 2002).

Send correspondence to Paulino Martínez. Departamento de Genética, Facultad de Veterinaria, Universidad de Santiago de Compostela, 27002 Lugo, Spain. E-mail: paulino.martinez@usc.es.
The Iberian Peninsula was one of the main glacial refuges during the Quaternary (Hewitt, 1996; Willis and Whittaker, 2000). The Duero basin, the largest river drainage in the Iberian Peninsula, drains to its Atlantic slope and shows specific biogeographic characteristics. Remarkable differences related with primary resources, slope, river flow and annual flow regime have been reported associated to northern and southern drainage areas (Arenillas Parra and Sáenz Ridruejo, 1987). A parapatric differentiation based on isozymes was reported in brown trout from Duero by Bouza et al. (2001). According to this information, two highly divergent genetic groups appeared segregated in northern and southern areas, with the highest divergence located at the Pisuerga tributary and the Lower-course (pure regions). However, a subsequent microsatellite and mtDNA survey in the same area suggested a slightly different scenario, with the same highly divergent pure regions, but with hybrid populations showing a more disperse and complex pattern (Martínez et al., 2007). The location of the AT and DU mtDNA lineages, respectively, in the Lower-course and Pisuerga pure regions, suggested a secondary contact between both lineages after the last glaciation. The similar spatial segregation of AT and DU lineages in the Miño basin, a neighbour drainage located northwards, gives addi- 
tional support to this hypothesis (Bouza et al., 2008). Considering the time of divergence suggested for AT and DU lineages in the mid-upper Pleistocene (Bouza et al., 2001; Suárez et al., 2001) and the restriction of the DU lineage to NW Iberia, it is likely that other secondary contacts could have taken place in interglacial periods across the Quaternary (Martínez et al., 2007).

Morphological characters are recommended for studying hybrid zones, especially in combination with genetic data (Campton, 1987; Barton and Hewitt, 1989). The analysis of morphological variation has been widely used by ichthyologists to differentiate species, lineages or populations within species (e.g., Ihssen et al., 1981; MacCrimmon and Claytor, 1985; Murta, 2000; Hermida et al., 2005; Turan et al., 2006). In brown trout, morphological, life-history or behavioural traits have sometimes demonstrated to be correlated with genetic differentiation (Ferguson and Mason, 1981; Giuffra et al., 1994; 1996; Largiadèr and Scholl, 1996). However, some subspecies described based on morphological traits were attributed to environmental plasticity (Bernatchez, 2001). Morphological characters have the limitation of their polygenic basis and environmental influence. However, natural selection acts on the phenotype, and quantitative traits are essential to explain adaptation and evolutionary significant variation (Reed and Frankham, 2001). The lack or low correlation between neutral genetic markers, commonly used to identify genetic resources, and quantitative traits have advised to use both genetic and quantitative data to identify biological resources (Crandall et al., 2000; Reed and Frankham, 2001; Cavers et al., 2005). Such information facilitates management strategies for conserving biodiversity. The most suitable approach for analyzing morphological variation is the use of multivariate analysis on a wide set of morphometric and meristic traits. These multivariate methods have proven to be efficient tools for stock identification in management programs and for investigating taxonomic problems in sympatric populations of brown trout (Cawdery and Ferguson, 1988; Karakousis et al., 1991; Aparicio et al., 2005).

In the present work, brown trout populations from the Duero basin were studied using morphometric and meristic traits commonly applied in salmonids, to evaluate morphological variation in a secondary contact between divergent lineages. By contrasting morphological information with previous molecular findings we made an attempt to obtain a global and congruent explanation for the genetic segregation of highly divergent lineages of this species in the NW Iberian Peninsula.

\section{Materials and Methods}

\section{Sampling}

Eleven samples of brown trout were collected by electro-fishing between autumn 2001 and spring 2002 from the Duero basin (Table 1; Figure 1). The sampling points were selected according to the following criteria: i) the native origin of the fish analyzed [both previous stocking and genetic information of sampling points were used to confirm the native condition of fish (Bouza et al., 2001; Martínez et al., 2007)]; ii) to obtain the most reliable picture of the morphological variation in this river basin, considering the main regions previously reported using different genetic markers (Bouza et al., 2001: Martínez et al., 2007). Accordingly, sampling included the pure regions (P1 and P2 from Pisuerga; AG1 and AG2 from the Lower-course) and hybrid populations (CA, CE, ES, NE, OM, TO and RI). These sampling points had been previously analyzed using isozymes, microsatellites and mtDNA. Sample codes are the same as in Martínez et al. (2007).

Table 1 - Codes and sampling characteristics of the 11 brown trout populations from the Duero basin.

\begin{tabular}{lccc}
\hline Code & Tributary & Region & Sample size \\
\hline AG1 & Águeda & Lower-course & 51 \\
AG2 & Águeda & Lower-course & 50 \\
CA & Caracena & Hybrid population & 41 \\
CE & Cega & Hybrid population & 51 \\
RI & Riaza & Hybrid population & 40 \\
TO & Tormes & Hybrid population & 52 \\
ES & Esla & Hybrid population & 50 \\
OM & Orbigo & Hybrid population & 46 \\
NE & Negro & Hybrid population & 34 \\
P1 & Pisuerga & Pisuerga & 52 \\
P2 & Pisuerga & Pisuerga & 49 \\
\hline Total & & & 516 \\
\hline
\end{tabular}

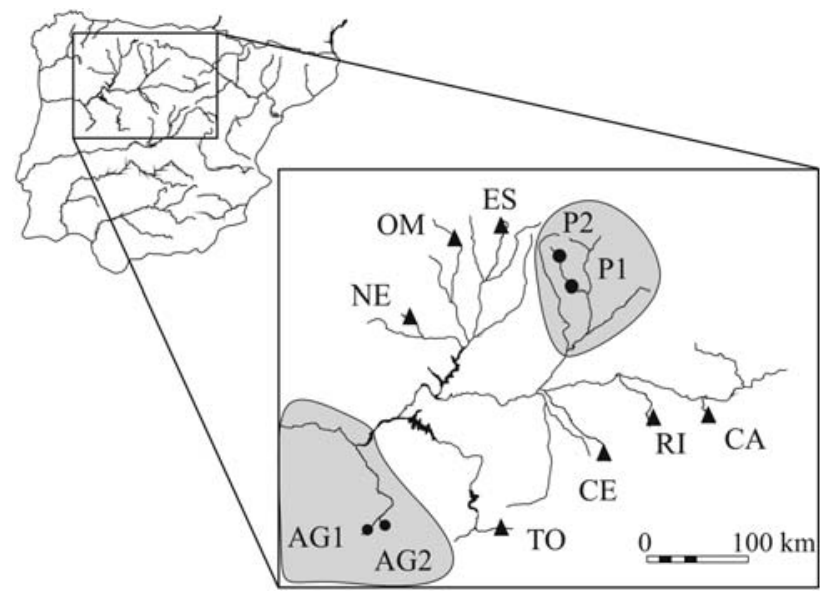

Figure 1 - Location of the 11 sampling sites in the Duero basin (Iberian Peninsula) analysed in the present study. Pure samples (Pisuerga and Lower-course) are shown as solid circles in the grey areas and hybrid populations as solid triangles. Coordinates of the map: upper left border: $43^{\circ} 16^{\prime} \mathrm{N} / 7^{\circ} 15^{\prime} \mathrm{W}$; lower right border: $40^{\circ} 4^{\prime} \mathrm{N} / 1^{\circ} 35^{\prime} \mathrm{W}$. 


\section{Morphological analysis}

Trout were sacrificed by an overdose of anaesthetic (ethylene glycol monophenyl ether). Twelve morphometric and four meristic characters were measured on fresh specimens shortly after death. The morphometric characters included caudal peduncle, body and head depth, eye diameter, distance between pectoral and pelvic fin, distance between pelvic and anal fin, maximum body width at the level of the dorsal fin origin, maximum gape width at the level of the posterior end of the maxilla, head and jaw lengths, and preorbital and postorbital distances. All measurements were taken to the nearest $0.01 \mathrm{~mm}$, using a digital calliper. Before analysis, all morphometric measures were standardized according to the following expression:

$$
\log Y_{i j}^{\prime}=\log Y_{i j}-\left(b_{j}\left(\log X_{i}-\log X\right)\right)
$$

where $Y_{i j}$ is the adjusted value of character $\mathrm{j}$ for individual $i, Y_{i j}$ is the original value, $b_{j}$ the allometric coefficient (the slope of the relationship between $\log X_{i}$ and $\log Y_{i j}$ ), $X_{i}$ the standard length of individual $i$, and $X$ a rounded-up mean of standard length from all samples $(150 \mathrm{~mm})$. The standard length is the length of fish measured from the tip of the snout to the posterior end of the midlateral portion of the hypural plate. Standardization of all morphometric measurements minimizes variability resulting from allometric growth and differences in mean size of individuals among populations (Reist, 1985). This correction is crucial in studies where the variation in mean size between samples due to different ecological features or biased sampling is relevant, as could be the case of the RI sample in our study.

The meristic counts included the number of gillrakers, pectoral and pelvic fin rays, and vertebrae. Counts of meristic bilateral traits were computed as the mean values from both body sides. All meristic traits were counted under a binocular microscope. The vertebrae were the last character counted, after scraping off muscle tissue. Separate analyses were conducted on the morphometric and meristic data, because these variables differ both statistically and biologically (Ihssen et al., 1981). Sex was determined by visual inspection of the gonads.

A global estimation of divergence for each character between all populations was obtained by analysis of the variance. The mean relative interpopulation component of the variance was obtained both for morphometric and meristic traits. To analyze the cause of the global divergence, pairwise Tukey post-hoc tests were carried out for each character and population pair.

Principal component analysis (PCA) of variancecovariance matrix on morphometric and meristic variables was firstly used to reveal patterns of geographic variation between samples. For this analysis, the populations from Pisuerga (P1 and P2) and Lower-course (AG1 and AG2) were pooled, to obtain a single reference from each pure region. Components with eigenvalues $>1$ were selected and scores of the loading matrix after varimax rotation evalu- ated. Centroid scores derived from the most informative principal components in each data set were labelled and plotted against.

Multiple discriminant analysis (MDA) was applied to the pure regions (Pisuerga and Lower-course) to get a discriminant function based on morphometric measurements. A classification matrix was constructed by assigning specimens to populations, on the basis of the linear combination of variables from the discriminant function. The jackknife method was used because it partially removes the bias inherent in classifying cases into groups that were used to define them (Tabachnick and Fidell, 1996). Then, this discriminant formula was used to compute canonical scores based on measurements from the hybrid samples, for comparing the values of pure regions with those of the hybrid populations. Diagram plots were used to display discriminant scores of each sample with respect to pure regions.

In addition, to assess the similarity between the hybrid populations, a second discriminant analysis was performed, using morphometric characters only from these populations. A classification matrix (jackknife method) was constructed by assigning specimens to populations, based on the linear combination of variables from each discriminant function. These discriminant functions were employed again to compute canonical scores, based on measurements from the two pure regions. A cluster analysis (Ward's method using Euclidean distance) was used to show the degree of similarity among the hybrid populations according to discriminant scores, using the group of centroids for each discriminant function as variables. Centroid groups from Lower-course and Pisuerga regions were added to the cluster analysis, to show their position with respect to other groups.

The same procedure described above was also applied to the meristic traits. However, the differentiation between pure regions was not so clear, and multivariate discriminant analysis was then applied to all populations together. As in the other cases, a classification matrix (jackknife method) was constructed and a cluster analysis (Ward's method using Euclidean distance) was used to show the degree of similarity among the different groups.

\section{Results}

Analysis of the variance showed a highly significant divergence among the populations from the Duero basin $(p<0.001$ for all characters except pelvic rays, $p=0.004)$. The relative component of variance was very high, ranging between 25.3 for pelvic rays and 60.7 for body depth (Table 2). The mean interpopulation component was 45.2 (S.D.: 10.8) and 31.5 (S.D.: 6.3) for morphometric and meristic traits, respectively, and 41.8 (S.D.: 11.5) when considering all characters. The results of the post-hoc tests revealed highly significant differences between all population pairs and characters $(\mathrm{p}<0.001$ tests: $51 \%$; non- 
Table 2 - Analysis of the variance of morphometric and meristic traits in the 11 populations from the Duero basin. Between- and within-populations absolute components and relative (\%) between-population components are presented.

\begin{tabular}{|c|c|c|c|c|c|}
\hline & Between populations & Within populations & $\%$ relative between pop. & $\mathrm{F}$ & $\mathrm{p}$ \\
\hline \multicolumn{6}{|l|}{ Morphometric traits } \\
\hline Body depth & 3.613 & 2.339 & 60.70 & 76.860 & $<0.001$ \\
\hline Body width & 0.925 & 1.312 & 41.35 & 34.727 & $<0.001$ \\
\hline Caudal peduncle depth & 0.409 & 0.340 & 54.61 & 58.566 & $<0.001$ \\
\hline Eye diameter & 0.200 & 0.150 & 57.14 & 61.010 & $<0.001$ \\
\hline Gape width & 0.404 & 0.610 & 39.84 & 32.154 & $<0.001$ \\
\hline Head depth & 0.494 & 0.769 & 39.11 & 31.761 & $<0.001$ \\
\hline Head length & 1.763 & 1.416 & 46.78 & 58.813 & $<0.001$ \\
\hline Jaw length & 1.178 & 0.821 & 58.93 & 71.45 & $<0.001$ \\
\hline Pectoral-pelvic fin distance & 1.216 & 2.430 & 33.35 & 23.286 & $<0.001$ \\
\hline Pelvic-anal fin distance & 1.850 & 2.408 & 43.45 & 33.737 & $<0.001$ \\
\hline Postorbital distance & 0.546 & 0.754 & 42.00 & 33.830 & $<0.001$ \\
\hline Preorbital distance & 0.144 & 0.421 & 25.49 & 17.991 & $<0.001$ \\
\hline \multicolumn{6}{|l|}{ Meristic traits } \\
\hline Gillrakers & 0.658 & 1.061 & 38.28 & 31.343 & $<0.001$ \\
\hline Pectoral rays & 0.115 & 0.210 & 35.38 & 28.151 & $<0.001$ \\
\hline Pelvic rays & 1.082 & 3.199 & 25.27 & 2.593 & 0.004 \\
\hline Vertebrae & 0.182 & 0.488 & 27.16 & 18.556 & $<0.001$ \\
\hline
\end{tabular}

significant (NS) tests: $37.8 \%$ ) that appeared evenly distributed across pairwise comparisons and traits. However, according to the number of significant test results obtained, three characters contributed in a higher proportion to the observed variation: head length: $\mathrm{p}<0.001: 69.4 \%$; NS: 25\%; eye diameter: $\mathrm{p}<0.001: 58.3 \%$; NS: $25 \%$; and body depth: $\mathrm{p}<0.001: 63.9 \%$; NS: 25\%. Also, the Lower-course sample showed a stronger differentiation than the other samples ( $p<0.001: 65.6 \%$; NS: 22.9\%). No significant differences between sexes were observed (ANOVA, $p>0.05$ for all traits and samples). Main descriptive statistics for all morphometric and meristic traits can be found as Supplementary material (Table S1).

PCA on morphometric characters extracted three factors explaining $64.3 \%$ of the variance in the data $(36.5 \%$, $16.9 \%$ and $10.8 \%$, respectively). The first component was related with several measures of the head (head depth, eye diameter, head and jaw lengths, preorbital and postorbital distance), whereas the second one was associated with traits related to body shape (caudal peduncle depth, body depth and body width) (Table 3). These two components showed no correlation with size (standard length; $r=-0.04$, $\mathrm{p}=0.32$; and $\mathrm{r}=-0.02, \mathrm{p}=0.62$, respectively). The meristic counts were summarized in two principal components, accounting for $34.9 \%$ and $26.0 \%$ of explained variance, respectively. The number of gillrakers and pectoral fin rays was associated with the first component and the number of vertebrae and pelvic rays with the second one (Table 3). Plotting meristic PC1 on morphometric PC1 and PC2 evi- denced a large heterogeneity among populations in the Duero basin (Figure 2). Pisuerga and Lower-course (pure regions) were the samples with the highest divergence when considering both plots. Some hybrid population pairs, like RI-ES or RI-CE, evidenced a similar divergence when plotting PC1-meristic against PC2-morphometric components (Figure 2b), but this divergence was much lower in the first plot (Figure 2a). The divergence between pure samples was mainly due to the meristic PC1, although both morphometric components revealed notable differences between the pure samples. The Lower-course sample showed a remarkable separation from the other ones, when comparing both PC1 components. As PCA does not require a priori grouping of the data, this assumption-free ordination of data justified the starting point hypothesis in the MDA analysis, to say that the pure samples constituted the extremes of the morphological range in the Duero basin.

The MDA using morphometric traits provided an almost complete segregation between the Lower-course and the Pisuerga samples, showing a clear-cut difference between the discriminant scores (Lower-course mean: 1.56, S.D.: 1.05; Pisuerga mean: -1.56, S.D.: 0.95). The most salient traits to discriminate pure samples were jaw length, head length and head depth (Table 3). Application of this discriminant function yielded a percentage of $94.1 \%$ of individuals correctly classified to their sample using the jackknife procedure. The discriminant scores computed for hybrid populations showed intermediate values between the pure regions in five out of seven samples (TO, mean: 

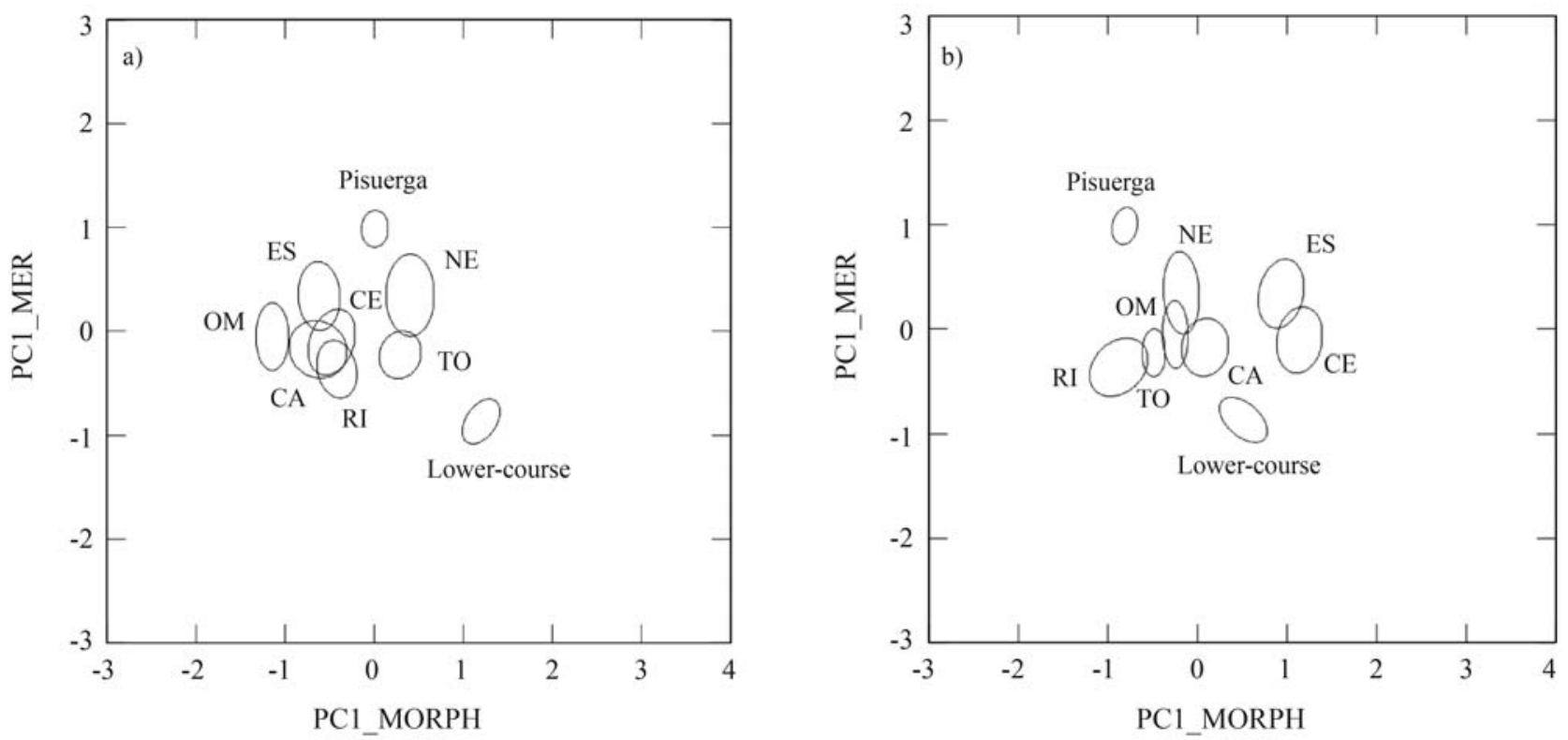

Figure 2 - Representation of centroid plots (with 0.95 confidence ellipses) from the Duero populations using: a) first meristic principal component on first morphometric principal component, and b) first meristic on second morphometric principal component.

0.22, S.D.: 1.11; CE, mean: 0.13, S.D.: 1.26; RI, mean: -0.29, S.D.: 1.38; NE, mean: -0.09, S.D.: 1.02; ES, mean: -0.29 , S.D.: 1.22). The OM (mean: -1.66, S.D.: 0.92) and specially the CA population (mean: -1.84, S.D.: 1.23) displayed values beyond the discriminant function of the Pisuerga sample. The mean discriminant value for all hybrid samples was -0.546 , clearly biased toward the score observed in the Pisuerga sample.

When the discriminant analysis was applied to the morphometric variables in the seven hybrid populations, six statistically significant discriminant functions ( $p<0.001$ in all cases) were found (Table 3 ). The first, second and third discriminant functions contributed to 40.8 , 26.5 and $13.3 \%$ of the variance, respectively. The first function was mainly associated with body depth and eye diameter, the second one was related with head length and distance between pectoral and pelvic fin, and in the third function caudal peduncle depth and body depth were the most important variables. The application of discriminant functions yielded a percentage of $79.0 \%$ of individuals correctly classified to their respective population using the jackknife procedure (Table 4). The cluster tree obtained from Euclidean distances between population centroids including the scores of the pure regions showed two main groups (Figure 3a). The Pisuerga and Lower-course appeared clustered in different groups, and the hybrid populations were associated to the Pisuerga (ES, OM, CA, CE) and Lower-course (NE, RI, TO) groups without a particular geographic trend.

Four discriminant functions were obtained from the meristic characters, three of which were statistically significant $(\mathrm{p}<0.001$; Table 3$)$. Each one of the four traits ap- peared associated mainly with one function, though the number of gillrakers was also related with the first function. The pectoral rays trait was related with the first function (60.6\% of explained variance), vertebrae with the second $(29.1 \%)$, number of gillrakers with the third $(8.8 \%)$, and pelvic rays with the fourth $(1.5 \%)$. With the meristic traits, $41.1 \%$ specimens were correctly classified to their respective populations using the jackknife procedure. The dendrogram with discriminant functions as variables using meristic traits showed a remarkable geographic trend, not observed in the morphometric one (Figure $3 b$ ). As in the first analysis, the Pisuerga and Lower-course samples were clustered in different groups, but the hybrid populations from the right margin (from upper to lower course) (OM, NE, ES) were associated to Pisuerga and those from the left margin (CE, TO, RI, CA) to Lower-course.

\section{Discussion}

The large and significant differentiation among populations observed for all morphological traits studied in brown trout from the Duero basin is in accordance with the high genetic diversity detected previously with isozymes, mtDNA and microsatellites (Bouza et al., 2001; Martínez et al., 2007). The interpopulation component of the variance (all characters: $41.80 \%$; morphometric traits: $45.22 \%$; meristic traits: $31.52 \%$ ) was very similar to the relative genetic differentiation component observed for isozymes $\left(\mathrm{G}_{\mathrm{st}}=0.46\right)$ and microsatellites $\left(\mathrm{G}_{\mathrm{st}}=0.348 ; \mathrm{R}_{\mathrm{st}}=0.413\right)$. This differentiation was high across all population pairs and characters, as evidenced by the post-hoc tests performed. However, three characters (head length, eye diameter and body depth) showed a higher contribution to the 


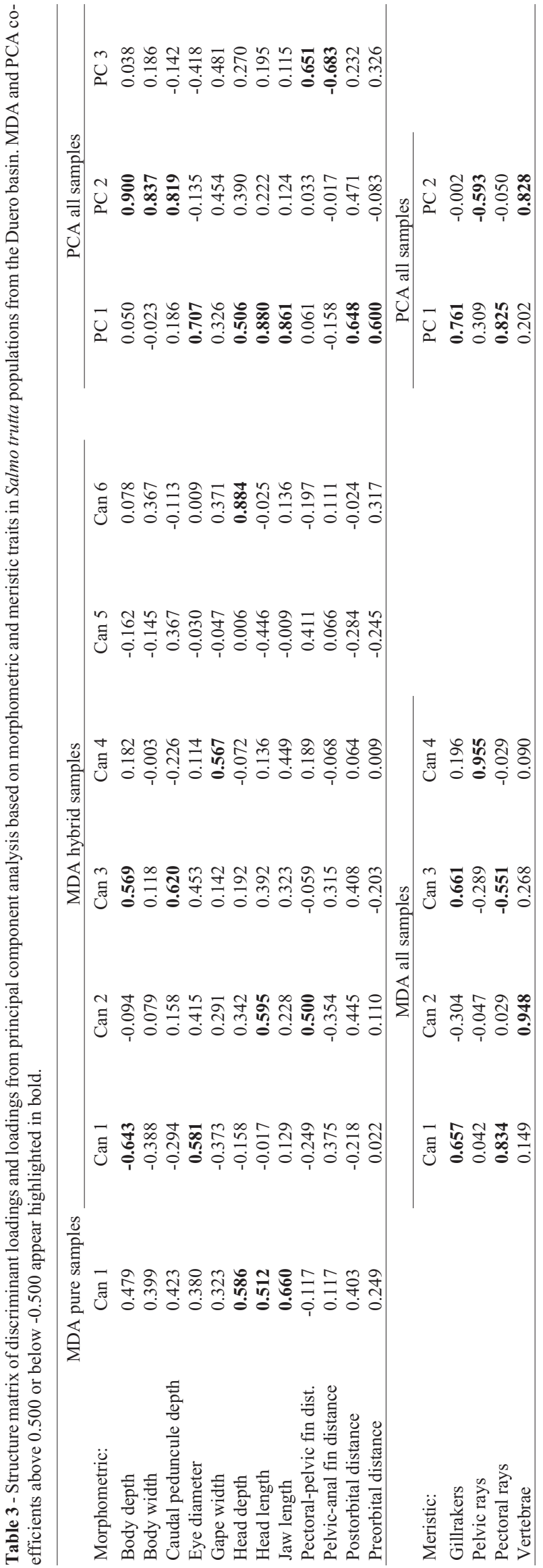

Table 4 - Classification matrix applying the discriminant morphometric functions to the seven hybrid populations from the Duero basin. Population codes from Table 1.

\begin{tabular}{lrrrrrrrr}
\hline \multirow{2}{*}{$\begin{array}{l}\text { Original } \\
\text { group }\end{array}$} & \multicolumn{6}{c}{ Predicted group membership (\%) } & \multirow{2}{*}{ Total } \\
\cline { 2 - 7 } & TO & \multicolumn{1}{c}{ CE } & \multicolumn{1}{c}{ RI } & \multicolumn{1}{c}{ CA } & NE & ES & OM & \\
\hline TO & 86.5 & 0.0 & 1.9 & 1.9 & 7.7 & 0.0 & 1.9 & 100 \\
CE & 2.0 & 66.7 & 0.0 & 11.8 & 5.9 & 7.8 & 5.9 & 100 \\
RI & 0.0 & 0.0 & 85.0 & 0.0 & 5.0 & 2.5 & 7.5 & 100 \\
CA & 0.0 & 9.8 & 0.0 & 73.2 & 0.0 & 4.9 & 12.2 & 100 \\
NE & 0.0 & 2.9 & 0.0 & 0.0 & 97.1 & 0.0 & 0.0 & 100 \\
ES & 4.0 & 8.0 & 0.0 & 4.0 & 2.0 & 66.0 & 16.0 & 100 \\
OM & 2.2 & 4.3 & 0.0 & 0.0 & 0.0 & 8.7 & 84.8 & 100 \\
\hline
\end{tabular}

Total corrected classified cases: $79.0 \%$

global differentiation observed. This was in accordance with the high discrimination power of these characters evidenced by multivariate analyses. Likewise, the high percentages of individuals correctly classified to their respective samples after the application of discriminant analyses reflected the high morphological differentiation among populations in the Duero basin, as reported using the microsatellite markers (Martínez et al., 2007). Though the hybrid populations did not show such a strong differentiation as the pure ones ( $94.1 \%$ classification success), they also displayed large heterogeneity $(79.0 \%$ classification success using morphometric traits). Even when meristic characters were used, which involved only four traits with low variation, the classification matrix was not disappointed $(41.1 \%)$. Finally, it is necessary to keep in mind that the influence of environmental variables on morphological traits (e.g. differences in temperature and oxygen content during early ontogeny) may contribute to the large variation observed.

The multivariate approaches enabled a more detailed analysis for finding out geographic trends in the whole differentiation observed in the Duero basin. All multivariate (principal component: PCA; discriminant: MDA) analyses and clustering methods consistently showed the highest morphological divergence between the pure regions, Pisuerga and Lower-course, as previously reported with molecular markers (Bouza et al., 2001; Martínez et al., 2007). This differentiation was mainly due to the meristic characters correlated with the first PC1 component, to say the number of pectoral rays and number of gillrakers. The hybrid populations displayed intermediate values for the MDA discriminant scores, except the CA and OM populations, which showed a mean discriminant value beyond the Pisuerga region. The CA population had also evidenced a hybrid value (admixture proportions; Bertorelle and Excoffier, 1998) beyond the Pisuerga region using microsatellite data (Martínez et al., 2007). The hybrid populations showed discriminant values (mean: -0.546$)$ closer to the Pisuerga $(-1.560)$ than to the Lower-course region 
(a)

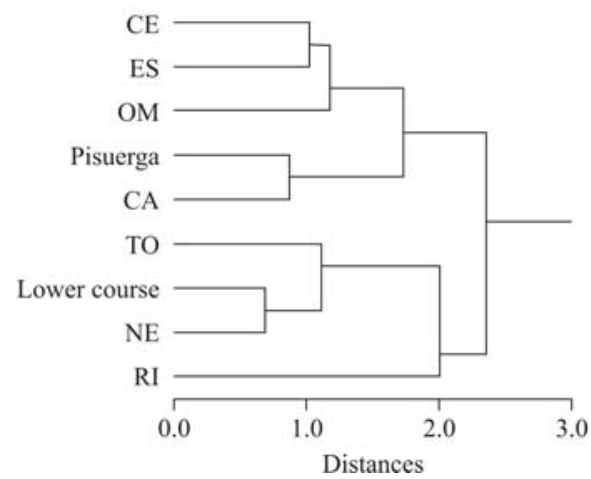

(b)

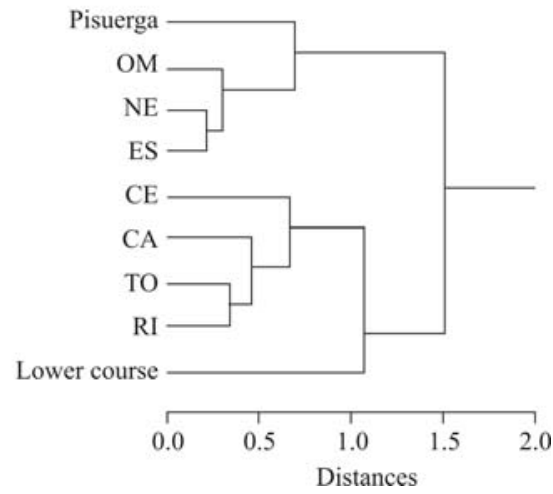

Figure 3 - Cluster trees by Ward's method using Euclidean distances obtained for: a) hybrid populations using centroid functions as variables with morphometric traits and centroids calculated from pure samples, and b) all populations together using meristic traits and centroid functions as variables.

(1.560). This is in accordance with the previous microsatellite and mtDNA information (Martínez et al., 2007), which evidenced a more relevant presence of the Pisuerga lineage in the Duero basin than previously reported in the study with allozymes (Bouza et al., 2001). Finally, the Lower-course region appeared as the most highly differentiated sample in the PCA analysis, as had also been observed with microsatellite markers (Martínez et al., 2007).

The results obtained demonstrate that the genetic differentiation reported in the Duero basin is associated to morphological variation. Morphological differences in brown trout have sometimes been associated to environmental plasticity (Bernatchez, 2001), but in other cases a correlation between both types of variation has been observed (Ferguson and Mason, 1981; Giuffra et al., 1994; 1996; Largiadèr and Scholl, 1996). Our data provide insights on the main discrimination characters that could be related with specific adaptations to the environmental heterogeneity reported in the Duero basin (Arenillas-Parra and Sáenz-Ridruejo, 1987). The main morphometric divergence between the pure regions was related to head characters, which were highly correlated with the first principal component and the discriminant function. Several traits of head shape (e.g. length of jaw, mouth position or eye diameter) have demonstrated to be related to prey-detecting and handing in different species of fish (Cawdery and Ferguson, 1988; Ostbye et al., 2005). According to the loading matrix, fish from Lower-course had longer jaws and heads and deeper heads than those from Pisuerga. Also, the relevance of some body shape variables (body depth, body width and caudal peduncle depth), both in the PCA and MDA analyses, indicate a more robust constitution of the Lower-course trout. Morphology has demonstrated to affect swimming ability in salmonids, when comparing different species, different populations or even migrating and non-migrating forms (Beacham, 1985; Ojanguren and Braña, 2003). In our study, the differences in meristic traits were mainly due to the number of pectoral rays, as evidenced by the PCA and MDA analyses. Salmonid juveniles have been suggested to use the pectoral fins to stabilize themselves when swimming against fast flowing water, so fins are useful to control propulsion (Ojanguren and Braña, 2003). All these differences could reflect adaptations to variable feeding and water-flow regime associated to the northern and southern areas of the Duero basin (Arenillas Parra and Sáenz Ridruejo, 1987).

The morphological variation found in our study is concordant with previous genetic data (Bouza et al., 2001; Martínez et al., 2007), confirming the spatial partitioning of brown trout from the Duero basin after a secondary contact between divergent lineages. The morphological traits responsible for this differentiation could be related with adaptation to the variable feeding and water-flow regimes across this large river basin. Selection in a highly heterogeneous environment could explain the restriction of the DU lineage to the inner part of the Duero basin along most of the Pleistocene.

\section{Acknowledgments}

The authors wish to thank Emilio Roy, Juan Carlos Velasco and the Castilla-León Government for their aid in collecting samples and permission for publishing the present data, and also all the forest guards that made the sampling trips possible. We are also in debt with Sonia Gómez, María López and Susana Sánchez for technical assistance. This study was supported by a Spanish Government grant (REN2001-3051) and by a contract with the Castilla-León Government (SC-132/02).

\section{References}

Aparicio E, García-Berthou E, Araguas RM, Martínez P and García-Marín JL (2005) Body pigmentation pattern to assess introgression by hatchery stocks in native Salmo trutta from Mediterranean streams. J Fish Biol 67:931-949.

Arenillas Parra M and Sáenz Ridruejo C (1987) Guía Física de España. 3. Los Ríos. Alianza Editorial, Madrid, 386 pp.

Barton NH and Hewitt GM (1989) Adaptation, speciation and hybrid zone. Nature 341:497-503. 
Beacham TD (1985) Meristic and morphometric variation in pink salmon (Oncorhynchus gorbuscha) in southern British Columbia and Puget Sound. Can J Zool 63:366-372.

Bernatchez L (2001) The evolutionary history of brown trout Salmo trutta L. inferred from phylogeographic, nested clade and mismatch analyses of mitochondrial DNA variation. Evolution 55:351-379.

Bertorelle G and Excoffier L (1998) Inferring admixture proportions from molecular data. Mol Biol Evol 15:1298-1311.

Bouza C, Arias J, Castro J, Sánchez L and Martínez P (1999) Genetic structure of brown trout, Salmo trutta L., at the southern limit of the distribution range of the anadromous form. Mol Ecol 8:1991-2001.

Bouza C, Castro J, Sánchez L and Martínez P (2001) Allozymic evidence of parapatric differentiation of brown trout (Salmo trutta L.) within an Atlantic river basin of the Iberian Peninsula. Mol Ecol 10:1455-1469.

Bouza C, Vilas R, Castro J and Martínez P (2008) Mitochondrial haplotype variability of brown trout populations from Northwestern Iberian Peninsula, a secondary contact area between lineages. Conserv Genet 9:917-920.

Campton DE (1987) Natural hybridization and introgression in fishes. In: Ryman N and Utter F (eds) Population Genetics and Fishery Management, University of Washington Press, Seattle, pp 161-192.

Cavers S, Navarro C, Hopkins R, Ennos RA and Lowe AJ (2005) Regional and population-scale influences on genetic diversity partitioning within Costa Rican populations of the pioneer tree Vochysia ferruginea mart. Silvae Genet 54:258264.

Cawdery SAH and Ferguson A (1988) Origins and differentiation of three sympatric species of trout (Salmo trutta L.) in Lough Melvin. Pol Arch Hydrobiol 35:267-277.

Crandall KA, Bininda-Emonds ORP, Mace GM and Wayne RK (2000) Considering evolutionary processes in conservation biology. Trends Ecol Evol 15:290-295.

Crozier W and Ferguson A (1986) Electrophoretic examination of the population structure of brown trout, Salmo trutta L., from the Lough Neagh catchment, Northern Ireland. J Fish Biol 28:459-477.

Ferguson A (1989) Genetic differences among brown trout, Salmo trutta, stocks and their importance for the conservation and management of the species. Freshw Biol 21:35-46.

Ferguson A and Mason FM (1981) Allozyme evidence for reproductively isolated sympatric populations of brown trout Salmo trutta L. in Lough Melvin, Ireland. J Fish Biol 18:629-642.

Giuffra E, Bernatchez L and Guyomard R (1994). Mitochondrial control region and protein coding genes sequence variation among phenotypic forms of brown trout, Salmo trutta, from Northern Italy. Mol Ecol 3:161-171.

Giuffra E, Guyomard R and Forneris G (1996) Phylogenetic relationships and introgression patterns between incipient parapatric species of Italian brown trout (Salmo trutta L. complex). Mol Ecol 5:207-220.

Hermida M, Fernández C, Amaro R and San Miguel E (2005) Morphometric and meristic variation in Galician threespine stickleback populations, NW Spain. Environ Biol Fish 73:189-200

Hewitt GM (1996) Some genetic consequences of ice ages, and their role in divergence and speciation. Biol J Linn Soc 58:247-276.

Ihssen PE, Booke HE, Casselman JM, Mcglade JM, Payne NR and Utter FM (1981) Stock identification: Materials and methods. Can J Fish Aquat Sci 38:1838-1855.

Karakousis Y, Triantaphyllidis C and Economidis PS (1991) Morphological variability among seven populations of brown trout, Salmo trutta L., in Greece. J Fish Biol 38:807-817.

Largiadèr CR and Scholl A (1996) Genetic introgression between native and introduced brown trout Salmo trutta L. populations in the Rhone River Basin. Mol Ecol 5:417-426.

MacCrimmon HR and Claytor RR (1985) Meristic and morphometric identity of Baltic stocks of Atlantic salmon (Salmo salar). Can J Zool 63:2032-2037.

Martínez P, Bouza C, Castro J, Hermida M, Pardo BG and Sánchez L (2007) Analysis of a secondary contact between divergent Atlantic mtDNA lineages of brown trout (Salmo trutta) from Duero basin using microsatellites and mtDNA RFLPs. J Fish Biol 71B:195-213.

Murta AG (2000) Morphological variation of horse mackerel (Trachurus trachurus) in the Iberian and North African Atlantic: Implications for stock identification. ICES J Mar Sci 57:1240-1248.

Ojanguren AF and Braña F (2003) Effects of size and morphology on swimming performance in juvenile brown trout (Salmo trutta L.) Ecol Fresh Fish 12:241-246.

Ostbye K, Naesje TF, Bernatchez L, Sandlund OT and Hindar K (2005). Morphological divergence and origin of sympatric populations of European whitefish (Coregonus lavaretus L.) in Lake Femund, Norway. J Evol Biol 18:683-702.

Presa P, Pardo BG, Martínez P and Bernatchez L (2002) Phylogeographic congruence between mtDNA and rDNA ITS markers in brown trout. Mol Biol Evol 19:2161-2175.

Reed DH and Frankham R (2001) How closely correlated are molecular and quantitative measures of genetic variation? A meta-analysis. Evolution 55:1095-1103.

Reist JD (1985) An empirical evaluation of several univariate methods that adjust for size variation in morphometric data. Can J Zool 63:1429-1439.

Ryman N (1983) Patterns of distribution of biochemical genetic variation in Salmonids: Differences between species. Aquaculture 33:1-21.

Suárez J, Bautista JM, Almodovar A and Machordom A (2001) Evolution of the mitochondrial control region in Palaearctic brown trout (Salmo trutta) populations: The biogeographical role of the Iberian Peninsula. Heredity 87:198-206.

Tabachnick BG and Fidell LS (2001) Using Multivariate Statistics. 4th edition. Allyn and Bacon Publishers, Boston, 966 pp.

Turan C, Oral M, Öztürk B and Düzgünes E (2006) Morphometric and meristic variation between stocks of Bluefish (Pomatomus saltatrix) in the Black, Marmara, Aegean and northeastern Mediterranean Seas. Fish Res 79:139-147.

Willis KJ and Whittaker RJ (2000) The refugial debate. Science 287:1406-1407. 


\section{Supplementary Material} ticle:

The following online material is available for this ar-

Table S1 - Number of individuals, mean, variance, standard deviation and range for the 12 morphometric and four meristic traits analysed in the nine samples from the Duero basin. The two Lower-course (AG1 and AG2) and
Pisuerga (P1 and P2) populations were pooled in a single Lower-course (AG) and Pisuerga (P) sample (see Material and Methods).

Associate Editor: Fausto Foresti

License information: This is an open-access article distributed under the terms of the Creative Commons Attribution License, which permits unrestricted use, distribution, and reproduction in any medium, provided the original work is properly cited. 


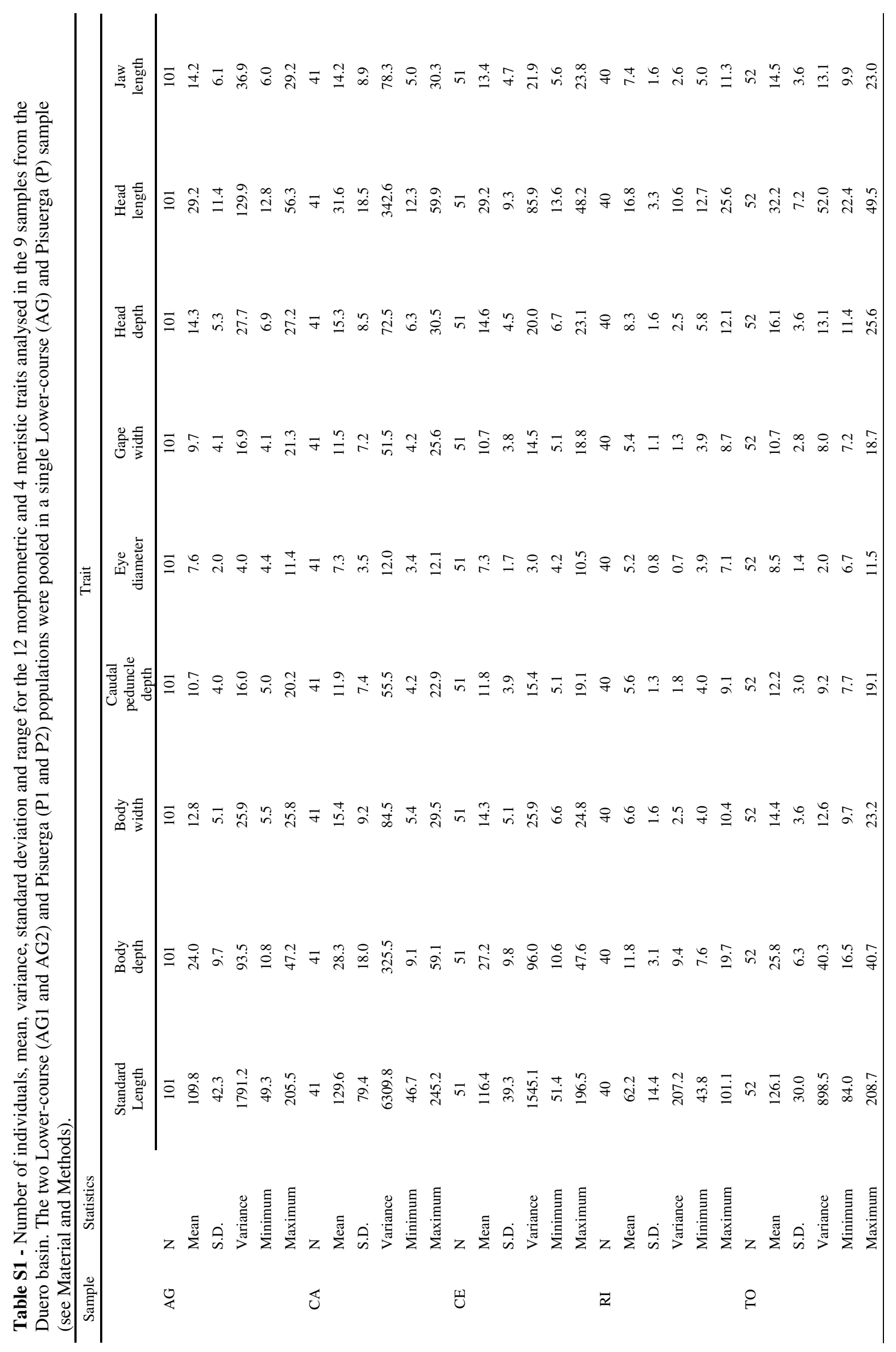




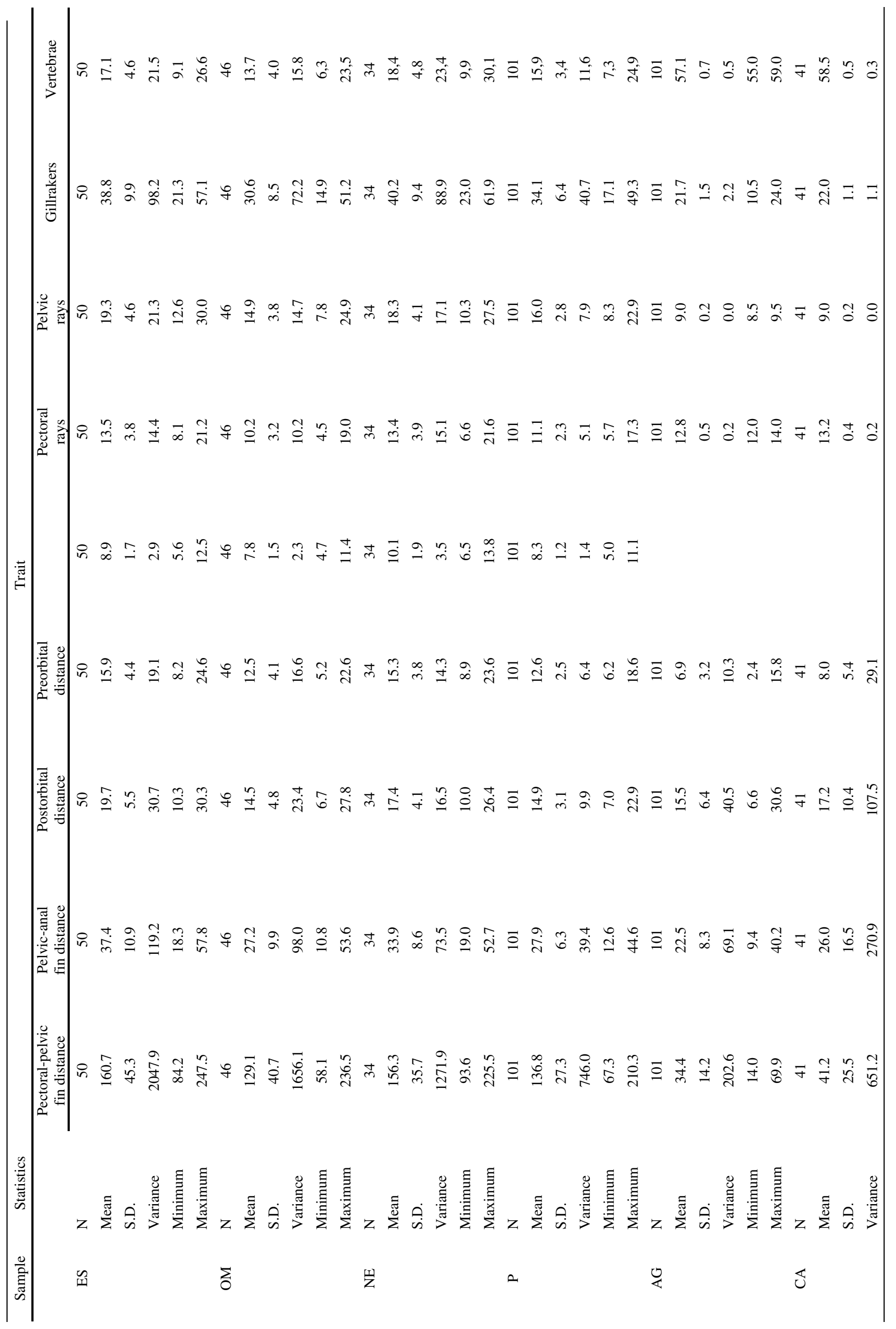




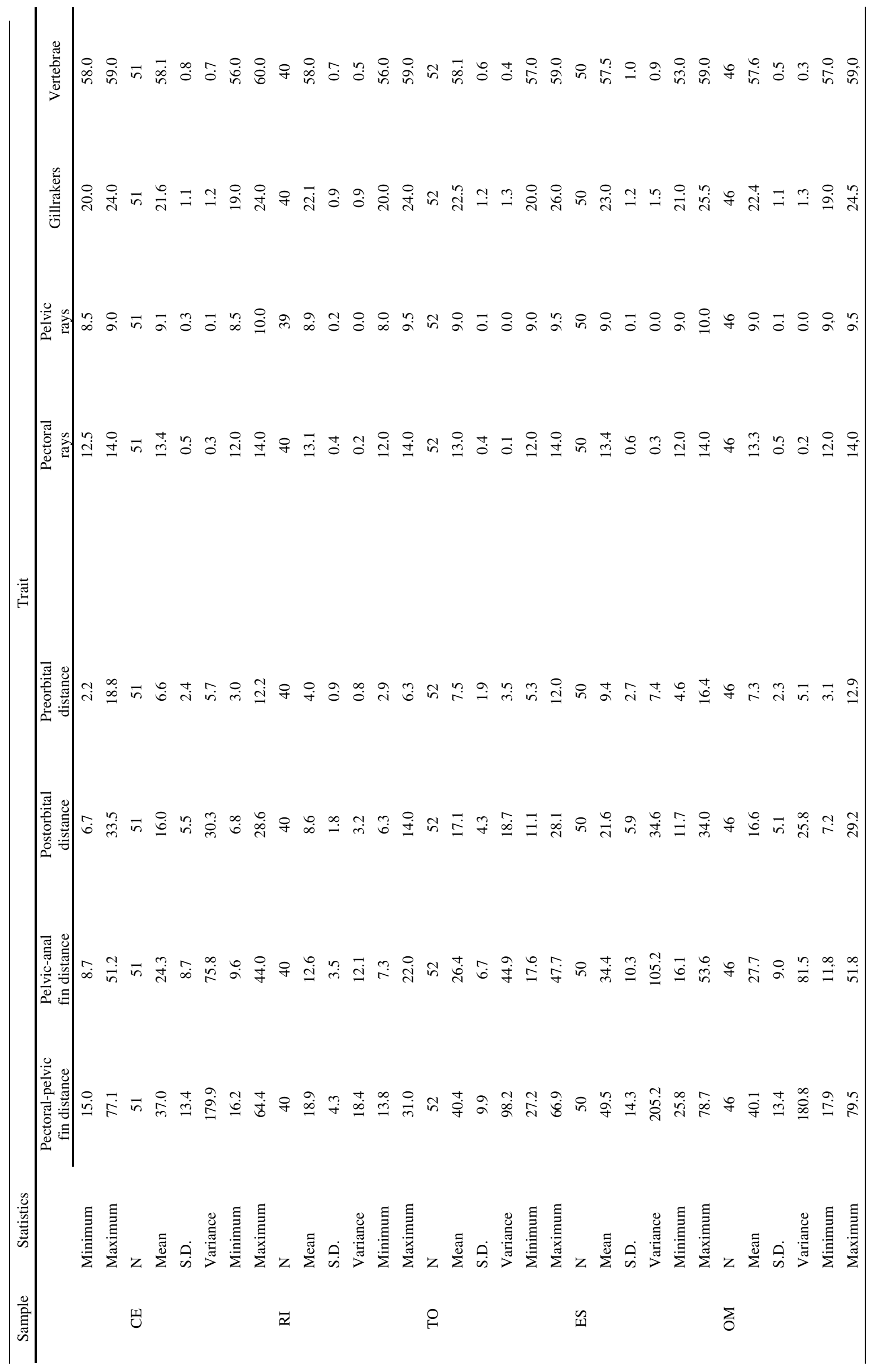




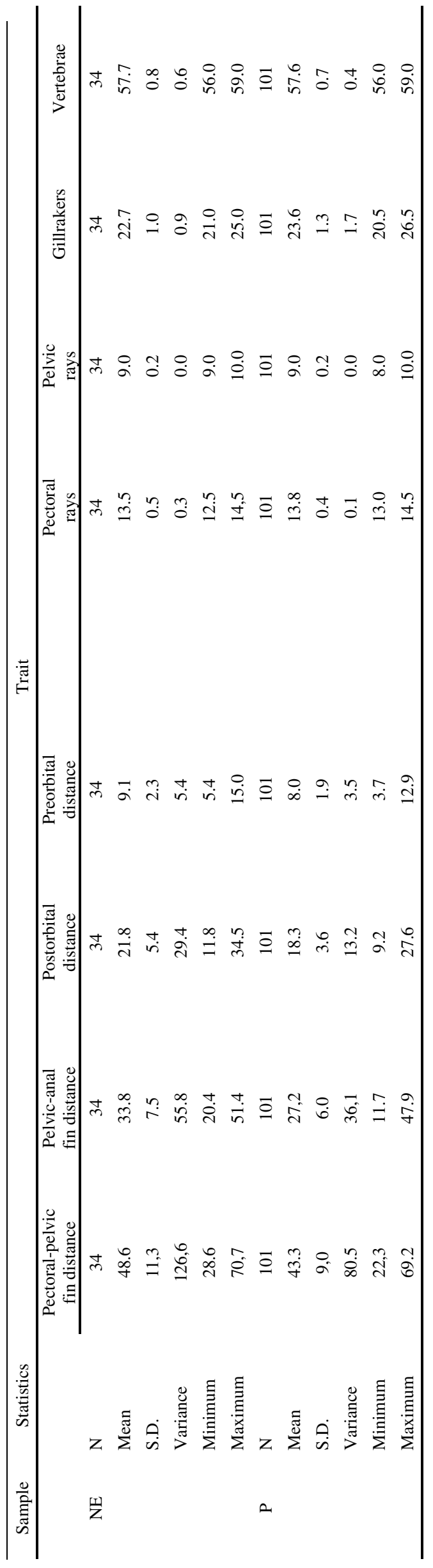

